\title{
ANALISIS HASIL PENJUALAN DENGAN MENGGUNAKAN RASIO RENTABILITAS PADA INDUSTRY KERAJINAN TANGAN DI KABUPATEN TASIKMALAYA
}

\author{
Iwan Sugianto
}

\section{Program Studi Manajemen STIE Latifah Mubarokiyah Suryalaya Tasikmalaya Sugiantoiwan15@yahoo.com}

\begin{abstract}
That in order to continue to drive the growth of national creative industry, in particular the Ministry of Industry Directorate General of Small and Medium Enterprises (SMEs) has made various strategic step in increasing the added value of the fashion industry and handicraft.

One of the areas in West Java, which has contributed in building a democratic economy in the craft industry sector is the Tasikmalaya district. This area is one barometer of industry crafts such as rushes, pandan, sticks and bamboo and

Misc.

This study aims to determine :

1. How Crafts Sales Results in Tasikmalaya regency.

2. How does the growth results Hand craft sale in Tasikmalaya regency period 2005- 2014.

3. How to Profitability Ratio Analysis Results Sales Results Crafts in Tasikmalaya regency period 2005-2014.

Analysts tool used in this study is the Economic Profitability Ratios so they will know the ratio between operating income with their own capital and foreign capital that is used to generate such profits and expressed as a percentage.
\end{abstract}

Keyword: Sales Results, Profitability Economy 


\section{LatarBelakang}

Masyarakat Ekonomi ASEAN (MEA) akan membentuk ASEAN sebagai pasar dan basis produksi tunggal membuat ASEAN lebih dinamis dan kompetitif dengan mekanisme dan langkah-langkah untuk memperkuat pelaksanaan baru yang ada inisiatif ekonomi; mempercepat integrasi regional di sektor-sektor prioritas; memfasilitasi pergerakan bisnis, tenaga kerja terampil dan bakat; dan memperkuat kelembagaan mekanisme ASEAN.

Bahwa dalam rangka menghadapi Masyarakat Ekonomi Asean tersebut, pemerintah meyakini, ekonomi kreatif masih potensial dan bisa menjadi kekuatan baru dalam meningkatkan perekonomian nasional ke depannya, karena didukung dengan sumber daya yang tidak terhabiskan. "Sumberdayautamanyaadalah orang kreatif yang dapat terus berkembang dan menciptakan nilai tambah.Terlebih lagi dengan terciptanya iklim yang kondusif, diharapkan akan terus tumbuh dan memberikan kontribusi ekonomi maupun non ekonomi," katanya.Disamping itu, karya kreatif dapat mengangkat citra bangsa Indonesia di mancanegara maupun membangun rasa bangga di dalam negeri seperti terlihat pada penggunaan batik dan tenun serta meluasnya kegiatan masyarakat pada sector kerajinan sekarang ini.

Selanjutnya, dalam upaya terus mendorong pertumbuhan industry kreatifnasional, Kemenperin khususnya Direktorat Jenderal Industri Kecil dan Menengah (IKM) telah melakukan berbagai langkah strategis dalam meningkatkan nilai tambah industri fashion maupun kerajinan, diantaranya melalui bimbingan teknis, dampingan pada pengrajin, promosi dan pemasaran, bantuan dalam mesin peralatan, serta perlindungan hak kekayaan intelektual.

Salah satu daerah di Jawa Barat yang memiliki peranan yang sangat baik dalam membangun perekonomian kerakyatan guna menopang perekonomian nasional adalah Kabupaten Tasikmalaya. Daerah ini merupakan penghasil kerajinan tangan mendong, pandan, lidi dan bambu terbesar di Indonesia, Tasikmalaya juga sudah sangat terkenal baik di tingkat nasional maupun internasional. Potensi

Ekonomi kerakyatan ini sangat baik dalam meningkatkan perekonomian, karena ekonomi kerakyatan tidak secara langsung terpengaruh oleh krisis 
perekonomian global (Dinas Koperasi, Perindustrian, dan Perdagangan Kabupaten Tasikmalaya). Potensi industri kerajinan tangan yang dimiliki oleh Kabupaten Tasikmalaya dapat dilihat pada tabel 1.1 sebagai berikut :

Tabel 1.1

Potensi Industri Kerajinan Tangan

di KabupatenTasikmalaya

\begin{tabular}{|c|l|l|}
\hline No & \multicolumn{1}{|c|}{ Uraian } & \multicolumn{1}{c|}{ Jumlah } \\
\hline 1 & Jumlah industri & 217 unit \\
\hline 2 & Jumlah Tenaga Kerja & 93.365 Orang \\
\hline 3 & Nilai Investasi & Rp.82.805.867.300 \\
\hline 4 & Nilai Produksi & Rp.665.165.200.000 \\
\hline 5 & Potensi Pemasaran & $75 \%$ Lokal, \\
& & $25 \%$ Ekspor \\
\hline
\end{tabular}

Sumber: Dinas Koperasi, Perindustrian dan Perdagangan Kabupaten Tasikmalaya, 2014.

Tabel 1.1 memperlihatkan potensi yang sangat besar dari kerajinan tangan di Kabupaten Tasikmalaya, dimana memiliki 217 unit Industri, 93.365 tenaga kerja, nilai investasi sebesar Rp 82.805.867.300,-, nilai produksi sebesar Rp 665.165.200.000,- dan mencakup potensi pemasaran 75\% lokal dan 25\% ekspor.

Potensi pemasaran lokal memiliki persentase yang jauh lebih besar dari pada ekspor, yaitu $75 \%$ lokal berbanding $25 \%$ ekspor, hal ini mengindikasikan bahwa pemasaran lokal sangat menjanjikan terlebih banyak daerah di Indonesia memiliki pasar sasaran potensial yang sangat baik terutama daerah-daerah yang selalu menjadi tujuan utama wisata baik untuk turis mancanegara ataupun turis domestik.

Industri kerajinan tangan yang dimiliki oleh Kabupaten Tasikmalaya dapat dilihat pada tabel 1.2 sebagai berikut : 


\section{Tabel 1.2}

Daftar Industri Kerajinan Tangan

di KabupatenTasikmalaya

\begin{tabular}{|c|c|c|c|c|c|}
\hline $\begin{array}{l}\text { No } \\
\text { ( } 1 \text { ) }\end{array}$ & $\begin{array}{c}\text { Kecamatan } \\
\text { ( } 2 \text { ) }\end{array}$ & $\begin{array}{c}\text { Jumlah } \\
\text { Industri } \\
\text { ( } 3 \text { ) }\end{array}$ & $\begin{array}{c}\text { Jumlah Tenaga } \\
\text { Kerja } \\
(4)\end{array}$ & & $\begin{array}{l}\text { Nilai Produksi } \\
\text { ( } 5 \text { ) }\end{array}$ \\
\hline 1 & Bantarkalong & 5 & 300 & $\mathrm{Rp}$ & 15.098 .709 .800 \\
\hline 2 & Bojongasih & 4 & 1210 & $\mathrm{Rp}$ & 16.675 .677 .200 \\
\hline 3 & Bojonggambir & 6 & 1410 & $\mathrm{Rp}$ & 22.767 .683 .200 \\
\hline 4 & Ciawi & 4 & 200 & $\mathrm{Rp}$ & 14.675 .757 .000 \\
\hline 5 & Cibalong & 5 & 1700 & $\mathrm{Rp}$ & 5.968 .637 .000 \\
\hline 6 & Cigalontang & 7 & 11200 & $\mathrm{Rp}$ & 32.867 .572 .300 \\
\hline 7 & Cikalong & 6 & 480 & $\mathrm{Rp}$ & 17.678 .768 .000 \\
\hline 8 & Cikatomas & 6 & 1180 & $\mathrm{Rp}$ & 17.576 .852 .000 \\
\hline 9 & Cineam & 7 & 11400 & $\mathrm{Rp}$ & 30.989 .500 .000 \\
\hline 10 & Cipatujah & 6 & 1280 & $\mathrm{Rp}$ & 16.967 .842 .300 \\
\hline 11 & Cisayong & 7 & 11500 & $\mathrm{Rp}$ & 31.678 .687 .240 \\
\hline 12 & Culamega & 6 & 1300 & $\mathrm{Rp}$ & 15.867 .565 .000 \\
\hline 13 & Gunung Tanjung & 5 & 480 & $\mathrm{Rp}$ & 14.986 .843 .200 \\
\hline 14 & Jamanis & 7 & 1200 & $\mathrm{Rp}$ & 32.762 .763 .070 \\
\hline 15 & Jatiwaras & 6 & 1100 & $\mathrm{Rp}$ & 17.656 .165 .700 \\
\hline 16 & Kadipaten & 5 & 980 & $\mathrm{Rp}$ & 16.571 .657 .000 \\
\hline 17 & Karang Jaya & 7 & 1480 & $\mathrm{Rp}$ & 33.562 .762 .000 \\
\hline 18 & Karangnunggal & 5 & 880 & $\mathrm{Rp}$ & 13.666 .571 .800 \\
\hline 19 & Leuwisari & 7 & 14800 & $\mathrm{Rp}$ & 14.765 .723 .300 \\
\hline 20 & Mangunreja & 6 & 480 & $\mathrm{Rp}$ & 14.676 .387 .100 \\
\hline 21 & Manonjaya & 7 & 15700 & $\mathrm{Rp}$ & 25.888 .151 .000 \\
\hline 22 & Padakembang & 5 & 480 & $\mathrm{Rp}$ & 13.678 .168 .100 \\
\hline 23 & Pagerageung & 3 & 480 & $\mathrm{Rp}$ & 5.878 .134 .000 \\
\hline 24 & Pancatengah & 4 & 480 & $\mathrm{Rp}$ & 13.376 .550 .000 \\
\hline 25 & Parungponteng & 6 & 700 & $\mathrm{Rp}$ & 14.512 .673 .000 \\
\hline
\end{tabular}




\begin{tabular}{|r|l|c|c|cr|}
26 & Puspahiang & 5 & 200 & $\mathrm{Rp}$ & 15.476 .767 .100 \\
\hline 27 & Rajapolah & $\mathbf{4}$ & $\mathbf{2 2 0}$ & $\mathbf{R p}$ & $\mathbf{3 4 . 9 6 5 . 7 6 2 . 0 0 0}$ \\
\hline 28 & Salawu & 7 & 1465 & $\mathrm{Rp}$ & 14.390 .900 .100 \\
\hline 29 & Salopa & 6 & 890 & $\mathrm{Rp}$ & 13.738 .871 .000 \\
\hline 30 & Sariwangi & 6 & 990 & $\mathrm{Rp}$ & 12.039 .809 .090 \\
\hline 31 & Singaparna & 6 & 880 & $\mathrm{Rp}$ & 13.876 .229 .100 \\
\hline 32 & Sodonghilir & 7 & 1490 & $\mathrm{Rp}$ & 23.768 .998 .100 \\
\hline 33 & Sukahening & 3 & 200 & $\mathrm{Rp}$ & 5.927 .227 .000 \\
\hline 34 & Sukaraja & 5 & 1620 & $\mathrm{Rp}$ & 9.189 .381 .800 \\
\hline 35 & Sukarame & 6 & 1220 & $\mathrm{Rp}$ & 11.987 .831 .000 \\
\hline 36 & Sukaratu & 4 & 180 & $\mathrm{Rp}$ & 6.717 .931 .300 \\
\hline 37 & Suka Resik & 5 & 220 & $\mathrm{Rp}$ & 12.096 .712 .000 \\
\hline 38 & Tanjungjaya & 6 & 1200 & $\mathrm{Rp}$ & 9.094 .071 .100 \\
\hline 39 & Taraju & 5 & 190 & $\mathrm{Rp}$ & 11.098 .909 .000 \\
\hline & Jumlah & 217 & 93365 & $\mathrm{Rp}$ & 665.165 .200 .000 \\
\hline
\end{tabular}

Sumber: Dinas Koperasi, Perindustrian dan Perdagangan Kabupaten Tasikmalaya, 2014.

Tabel 1.2 memperlihatkan jumlah unit industri kerajinan tangan, jumlah tenaga kerja dan nilai produksi dari setiap kecamatan di Kabupaten Tasikmalaya. Dari tabel di atas dapat kita lihat bahwa Kecamatan Rajapolah merupakan kecamatan yang memiliki dengan nilai produksi paling besar sekabupaten Tasikmalaya dengan jumlah nilai produksi sekitar Rp 34.965.762.000,-.

Industri kerajinan tangan yang tercatat di Kantor Pelayanan Perijinan Terpadu dan Dinas Koperasi, Perindustrian dan Perdagangan Kabupaten Tasikmalaya untuk Kecamatan Rajapolah dapat dilihat pada tabel 1.3 sebagai berikut :

Tabel 1.3

Industri Kerajinan Tangan Kecamatan Rajapolah

\begin{tabular}{|c|c|c|c|c|}
\hline \multirow{2}{*}{ Nama Perusahaan } & Tahun & Kapasitas & Total & Tenag \\
& Berdiri & Kcs/Thn & Kapasita & $\mathbf{a}$ \\
\hline
\end{tabular}




\begin{tabular}{|l|c|c|c|c|c|}
\hline & & Exp & Lokal & s & Kerja \\
\hline CV. Jamal Handycraft & 1990 & 250.000 & 30.000 & 280.000 & 39 \\
\hline CV. Nucrea Craft & 1997 & 250.000 & 40.000 & 290.000 & 40 \\
\hline M-02 & 1997 & 200.000 & - & 200.000 & 50 \\
\hline $\begin{array}{l}\text { CV. Dandy } \\
\text { Handycraft }\end{array}$ & 1998 & 480.000 & 58.000 & 538.000 & 96 \\
\hline
\end{tabular}

Sumber : Dinas Koperasi, Perindustrian dan Perdagangan Kabupaten Tasikmalaya, 2014.

Dinas Koperasi, Perindustrian dan Perdagangan Kabupaten Tasikmalaya (2014) mencatat empat industri kerajianan tangan yang terdapat di Kecamatan Rajapolah, yaitu CV Dandy Handycraft, CV. Jamal Handycraft, CV Nucrea Craft dan Perusahaan M-02.

Ditengah potensi pasar lokal yang sangat menjanjikan, masalah yang dihadapi oleh industry kerajinan yang ada di Kecamatan Rajapolah Kabupaten Tasikmalaya adalah perlunya menganalisis terhadap peningkatan hasil penjualan yang fluktuatif sehingga dapat diketahui factor penyebabnya.

Berdasarkanuraian di atas maka peneliti tertarik untuk mengambilpenelitiandengan judul “ Analisis Hasil Penjualan dengan menggunakan Rasio Rentabilitas pada IndustryKerajinan Tangan di Kabupaten Tasikmalaya ").

\section{RumusanMasalah}

Berdasarkanlatarbelakang di atas, makamasalah yang adasebagaiberikut:

1. BagaimanaHasilPenjualanKerajinanTangan di Kabupaten Tasikmalaya.

2. Bagaimana pertumbuhanHasilpenjualan kerajinanTangan di Kabupaten Tasikmalaya periode $2005-2014$.

3. Bagaimana

HasilAnalisisRasioRentabilitasterhadapHasilPenjualanKerajinanTangan di KabupatenTasikmalayaperiode 2005-2014. 


\section{Kajian Literatur}

Penjualan merupakan salah satu fungsi pemasaran yang sangat penting dan menentukan bagi perusahaan dalam mencapai tujuan perusahaan yaitu memperoleh laba untuk menjaga kelangsungan hidup perusahaan. Sebenarnya pengertian penjualan sangat luas, beberapa para ahli mengemukakan tentang definisi penjualan antara lain :

Menurut Philip Kotler yang diterjemahkan oleh Ronny A. Rusli dan Hendra dalam buku "Manajemen Pemasaran" pengertian penjualan adalah : "Penjualan adalah proses sosial manajerial dimana individu dan kelompok mendapatkan apa yang mereka butuhkan dan inginkan, menciptakan, menawarkan, dan mempertukarkan produk yang bernilai dengan pihak lain”.(2000: 8)

Menurut Kusnadi dalam buku Akuntansi keuangan lanjutan yang menjelaskan bahwa:

"Penjualan (sales) adalah sejumlah uang yang dibebankan kepada pembeli atas barang atau jasa yang dijual".(2000;19)

Dari penjelasan diatas dapat disimpulkan bahwa penjualan adalah suatu proses pembuatan dan cara untuk mempengaruhi pribadi agar terjadi pembelian (penyerahan) barang atau jasa yang ditawarkan berdasarkan harga yang telah disepakati oleh kedua belah pihak yang terkait didalam kegiatan tersebut.

Hasil penjualan adalah pendapatan yang diperoleh dari transaksi penjualan secara

tunai atau kredit kepada para langganan untuk suatu periode tertentu. Jumlah yang diterima dari hasil penjualan tersebut tidak termasuk pajak penjualan atau pajak pertambahan nilai yang dipungut berdasarkan petunjuk kantor pajak. Hasil yang diterima tidak seluruhnya merupakan pendapatan karena hasil jual yang ditetapkan

tidak semua dibebankan kepada pembeli dan ini harus dikurangkan dari hasil penjualan. Biaya angkut barang yang dijual dan dibebankan kepada pembeli tidak termasuk sebagai hasil penjualan, maka biaya tersebut merupakan elemen biaya 
penjualan. ( Sutrisno,2003;46).

\section{Faktor-Faktor Yang Mempengaruhi Penjualan}

Dalam praktek, kegiatan penjualan ini dipengaruhi oleh beberapa faktor yaitu :

1. Kondisi dan Kemampuan Pasar

Disini penjual harus dapat meyakinkan pembeli agar berhasil mencapai sasaran penjualan yang diharapkan untuk maksud tertentu, penjual harus memahami beberapa masalah penting yang sangat berkaitan yaitu :

a. Jenis dan karakteristik barang yang ditawarkan

b. Harga Produk

c. Syarat penjualan seperti pembayaran, pengantaran, garansi, dan sebagainya.

2. Kondisi Pasar

Hal yang harus diperhatikan pada kondisi pasar antara lain:

a. Jenis pasarnya, apakah pasar konsumen, pasar industri, pasar pemerintah atau pasar Internasional

b. Kelompok pembeli dan segmen pasarnya

c. Daya beli

d. Frekuensi pembeliannya

e. Keinginan dan kebutuhan

\section{Modal}

Apakah modal kerja perusahaan mampu untuk mencapai target penjualan yang dianggarkan seperti untuk :

a. Kemampuan untuk membiayai penelitian pasar yang dilakukan

b. Kemampuan membiayai usaha-usaha untuk mencapai target penjualan

c. Kemampuan membeli bahan mentah untuk dapat memenuhi target penjualan.

4. Kondisi Organisasi Perusahaan

Pada perusahaan besar, biasanya masalah penjualan ditangani oleh bagian penjualan. Lain halnya dengan perusahaan kecil, dimana masalah penjualan ditangani oleh orang yang juga melakukan fungsi-fungsi lain. 


\section{Fungsi Dan Tujuan Penjualan}

Fungsi penjualan meliputi aktivitas-aktivitas yang dilakukan oleh penjual untuk merealisasikan penjualan seperti :

a. Menciptakan permintaan

b. Mencari pembeli

c. Memberikan saran-saran

d. Membicarakan syarat-syarat penjualan

e. Memindahkan hak milik

Pada umumnya, para pengusaha mempunyai tujuan yaitu mendapatkan laba tertentu (semaksimal mungkin), dan mempertahankan atau bahkan berusaha meningkatkannya untuk jangka waktu yang lama. Tujuan tersebut dapat direalisasi apabila penjualan dapat dilaksanakan seperti yang telah direncanakan.

Perusahaan pada umumnya mempunyai tiga tujuan umum dalam penjualan, yaitu :

a. Mencapai volume penjualan tertentu

b. Mendapatkan laba tertentu

c. Menunjang pertumbuhan perusahaan

\section{Volume Penjualan}

Dari penjelasan mengenai penjualan, penjualan selalu dikaitkan dengan istilah penjualan dan volume penjualan. Besar kecilnya hasil penjualan dipengaruhi oleh jumlah produk yang terjual.

pengertian Volume Penjualan menurut Assegaf Abdullah dalam "Kamus Akuntansi" menyatakan bahwa :

"Volume penjualan adalah jumlah unit yang terjual dari unit produksi suatu pemindahan dari pihak produksi ke pihak konsumen, dan tetap pada suatu periode tertentu".(2001: 444)

Berdasarkan dari pengertian-pengertian di atas dapat ditarik kesimpulan bahwa volume penjualan merupakan hasil dari kegiatan penjualan yang dilakukan oleh perusahaan dalam usahanya mencapai sasaran yaitu memaksimalkan laba. 


\section{Pengertian Rentabilitas}

Perusahaan yang mempunyai tujuan margin keuntungan akan selalu berusaha untuk meningkatkan jumlah laba yang akan diperoleh, namun laba yang besar belum tentu merupakan ukuran bahwa perusahaan telah bekerja secara efisien.

Efisien atau tidaknya suatu perusahaan baru dapat diketahui dengan membandingkan antara laba yang diperoleh dengan modal yang digunakan untuk mendapatkan laba tersebut atau dengan kata lain dengan cara menghitung rasio rentabilitasnya.

Menurut Bambang Riyanto (1995;28):

Rentabilitas adalah kemampuan suatu perusahaan untuk menghasilkan laba selama periode tertentu dan umumnya dirumuskan sebagai L/M, dimana $\mathrm{L}$ adalah jumlah laba yang diperoleh dalam periode tertentu dan $\mathrm{M}$ adalah modal atau aktiva yang digunakan untuk menghasilkan laba tersebut.

Kriteria penilaian yang dianggap baik dan valid dengan menggunakan rentabilitas yang digunakan sebagai alat ukur tentang hasil pelaksanaan operasional perusahaan, mempunyai ciri-ciri sebagai berikut:

1. Rentabilitas merupakan alat pembanding pada berbagai alternatif investasi atau penanaman modal yang sudah tentu sesuai dengan tingkat risikonya masing-

masing. Secara umum dapat dikatakan semakin besar risiko suatu investasi maka

dituntut rentabilitas yang semakin tinggi, demikian pula sebaliknya.

2. Rentabilitas menggambarkan tingkat laba yang dihasilkan menurut jumlah modal yang ditanamkan karena rentabilitas dinyatakan dalam angka relatif.

Tujuan dan Kegunaan Analisis Rentabilitas

Pengertian rentabilitas sebagai kriteria penilaian hasil operasi perusahaan mempunyai tujuan pokok dan dapat digunakan sebagai berikut :

1. Sebagai indikator tentang efektifitas manajemen Tinggi rendahnya rentabilitas yang dihasilkanolehsuatuperusahaantergantung pada kemahiran 
dan motivasi dari manajer.

2. Rentabilitasmerupakansalahsatu faktor yang menarik perhatian para analis, karena mampu menggambarkan kriteria yang sangat diperlukan untuk menilai sukses tidaknya suatu perusahaan.

3. Suatu alat untuk membuat proyeksi laba perusahaan Rentabilitas menggambarkan korelasi antara tingkat laba dengan jumlah dengan jumlah modal yang ditanamkan, maka sangat membantu bagi para analis untuk membuat proyeksi laba pada berbagai tingkat jumlah modal yang ditanamkan pada jenis usaha yang bersangkutan.

4. Sebagai alat pengendalian bagi manajemenBagi pihak intern (manajemen khususnya), rentabilitas dapat digunakan sebagai alat pengendalian. Rentabilitas dipakai sebagai alat untuk menyusun rencana budget pelaksanaan operasi perusahaan, kriteria penilaian alternatif dan dasar pengembalian keputusan penanaman modal.

\section{RasioRentabilitasEkonomi}

Rasio rentabilitas merupakan salah satu alat ukur untuk menilai efisiensi atau tidaknya suatu perusahaan dapat dikelompokkan menjadi dua bagian yaitu rentabilitas ekonomis dan rentabilitas modal sendiri.

Rentabilitas Ekonomis (RE)

Rentabilitas Ekonomis adalah perbandingan antara laba usaha dengan modal sendiri dan modal asing yang dipergunakan untuk menghasilkan laba tersebut dan dinyatakan dalam persentase. (Bambang Riyanto,2013).

$$
\mathrm{RE}=\frac{\mathrm{Laba}}{\text { Modal }} \times 100 \%
$$

Oleh karena itu pengertian rentabilitas sering dipergunakan untuk mengukur efisiensi penggunaan modal didalam suatu perusahaan, maka Rentabilitas Ekonomis sering dimaksudkan sebagai kemampuan perusahaan dengan seluruh modal yang bekerja didalamnya untuk menghasilkan laba.

Laba yang diperhitungkan dalam Rentabilitas Ekonomi adalah laba yang 
berasal dari hasil operasional perusahaan yang sering disebut laba operasi atau usaha. Laba yang diperoleh dari usaha-usaha diluar operasional perusahaan atau efek seperti dividen, kupon dan lain-lain tidak dimasukkan dalam perhitungannya.

SelanjutnyauntukmengukurkriteriaterhadaphasilRentabilitasEkonomi yang telahdiketahuimakadigunakanStandar perhitungan Rasio Rentabilitas EkonomiberdasarkanPermen No. 14/Per/M.KUKM/XII/2009.

Tabel. 1.4

Standar perhitungan Rasio Rentabilitas Modal Sendiri (ROE)

\begin{tabular}{|l|l|l|l|}
\hline Komponen & Standar & Nilai & Kriteria \\
\hline$($ ROE $)$ & $<3$ & 25 & KurangBaik \\
& $3-4$ & 50 & CukupBaik \\
& $4-5$ & 75 & Baik \\
& $\geq 5$ & 100 & SangatBaik \\
\hline
\end{tabular}

Sumber : Permen No. 14/Per/M.KUKM/XII/2009

\section{Hasil Dan Pembahasan}

\section{HasilPenjualanKerajinanTangan di Kecamatan Rajapolah Kabupaten}

\section{Tasikmalaya.}

\begin{tabular}{|c|c|c|c|r|}
\hline Nama CV & Tahun & $\begin{array}{c}\text { Volume } \\
\text { Penjualan }\end{array}$ & Harga & HasilPenjualan \\
\hline \multirow{2}{*}{$\begin{array}{c}\text { CV. Jamal } \\
\text { Handycraft }\end{array}$} & 2010 & 28.300 & Rp. 23.000 & 650.900 .000 \\
\cline { 2 - 5 } & 2011 & 31.100 & Rp. 28.900 & 898.790 .000 \\
\cline { 2 - 5 } & 2012 & 32.900 & Rp. 35.000 & 1.151 .500 .000 \\
\cline { 2 - 5 } & 2013 & 41.200 & Rp. 35.000 & 1.442 .000 .000 \\
\cline { 2 - 5 } & 2014 & 43.650 & Rp. 38.500 & 1.680 .525 .000 \\
\hline CV Dandy & 2010 & 40.200 & Rp. 21.500 & 864.300 .000 \\
\hline
\end{tabular}




\begin{tabular}{|c|c|c|l|r|}
\cline { 2 - 5 } Handycrat & 2011 & 51.200 & Rp. 27.000 & 1.382 .400 .000 \\
\cline { 2 - 5 } & 2012 & 53.500 & Rp. 32.000 & 1.712 .000 .000 \\
\cline { 2 - 5 } & 2013 & 65.200 & Rp. 32.500 & 2.119 .000 .000 \\
\cline { 2 - 5 } Handycraft & 2014 & 75.650 & Rp. 36.000 & 2.723 .400 .000 \\
\cline { 2 - 5 } \begin{tabular}{c} 
Nucrea \\
\cline { 2 - 5 }
\end{tabular} & 2010 & 29.000 & Rp. 22.500 & 652.500 .000 \\
\cline { 2 - 5 } & 2011 & 33.200 & Rp. 28.000 & 929.600 .000 \\
\cline { 2 - 5 } & 2013 & 35.500 & Rp. 34.000 & 1.207 .000 .000 \\
\cline { 2 - 5 } & 2014 & 43.650 & Rp. 37.000 & 1.615 .000 .000 \\
\hline & & 646.350 & Rp. 31.700 & 20.484 .815 .000 \\
\hline
\end{tabular}

Sumber: dan (Data Primer).

Bahwa Berdasarkan Tabel di atas Hasil penjualan yang terjadi di beberapa CV di kecamatan Raja polah Kabupaten Tasikmalaya terus mengalami peningkatan hal ini dipengaruhi oleh volume penjualan yang mengalami peningkatan.

Bagaimana pertumbuhan Hasil Penjualan KerajinanTangan di Kecamatan Rajapolah Kabupaten Tasikmalaya periode 2005-2014.

\begin{tabular}{|c|c|c|c|c|}
\hline Nama CV & Tahun & $\begin{array}{c}\text { Volume } \\
\text { Penjualan }\end{array}$ & HasilPenjualan & $\begin{array}{l}\text { Pertumbuhan } \\
\text { HasilPenjualan }\end{array}$ \\
\hline \multirow{5}{*}{$\begin{array}{l}\text { CV. Jamal } \\
\text { Handycraft }\end{array}$} & 2010 & 28.300 & 650.900 .000 & - \\
\hline & 2011 & 31.100 & 898.790 .000 & $27,6 \%$ \\
\hline & 2012 & 32.900 & 1.151 .500 .000 & $22 \%$ \\
\hline & 2013 & 41.200 & 1.442 .000 .000 & $20 \%$ \\
\hline & 2014 & 43.650 & 1.680 .525 .000 & $14 \%$ \\
\hline \multirow{4}{*}{$\begin{array}{l}\text { CV Dandy } \\
\text { Handycrat }\end{array}$} & 2010 & 40.200 & 864.300 .000 & - \\
\hline & 2011 & 51.200 & 1.382 .400 .000 & $37,47 \%$ \\
\hline & 2012 & 53.500 & 1.712 .000 .000 & $19,25 \%$ \\
\hline & 2013 & 65.200 & 2.119 .000 .000 & $19,21 \%$ \\
\hline
\end{tabular}




\begin{tabular}{|c|c|c|r|c|}
\cline { 2 - 5 } \multirow{4}{*}{$\begin{array}{c}\text { Nucrea } \\
\text { Handycraft }\end{array}$} & 2014 & 75.650 & 2.723 .400 .000 & $22,19 \%$ \\
\cline { 2 - 5 } & 2010 & 29.000 & 652.500 .000 & - \\
\cline { 2 - 5 } & 2011 & 33.200 & 929.600 .000 & $29,80 \%$ \\
\cline { 2 - 5 } & 2012 & 35.500 & 1.207 .000 .000 & $23 \%$ \\
\cline { 2 - 5 } & 2013 & 42.200 & 1.455 .900 .000 & $17,1 \%$ \\
\hline & 2014 & 43.650 & 1.615 .000 .000 & $9,8 \%$ \\
\hline & & 646.350 & 20.484 .815 .000 & \\
\hline
\end{tabular}

Sumber: dan (Data Primer).

BahwaBerdasarkanTabel di atasPertumbuhanHasilpenjualan yang terjadi di beberapa CV di kecamatan Raja polah Kabupaten Tasikmalaya menunjukan angka fluktuatif untuk setiap tahunnya walaupun hasil penjualan mengalami peningkatan hal ini disebabkan karena peningkatannya tidak begitu signifikan, keadaan demikian dipengaruhi oleh naiknya harga secara mayoritas untuk setiapTahunnya.

PadaTahun 2011 menunjukanhasilpenjualan yang signifikanhal ini dipengaruhi oleh kenaikan volume penjualan yang meningkatan walaupun terjadi peningkatan harga dan terjadi peningkatan permintaan dari CV. GENEVA Bali dan CV. Creata Indo Jakarta.

Periode 2012-2014 pertumbuhan volume penjualan mengalami penurunan dari rata-rata setiap tahunnya berada diantara $4 \%$ s/d $5 \%$ hal ini disebabkan adanya peningkatan harga penjualan yang diakibatkan adanya kenaikan bahan baku sehingga volume penjualan tidak mengalami peningkatan yang signifikan.

Pada Tahun 2014 terjadi perbedaan pertumbuhan hasil penjualan dimana terdapat 2 (dua) CV yaitu CV. Jamal Handycraft dan CV.Nucrea Handycraft pertumbuhan hasil penjualan mengalami penurunan sekitar $6 \%$ hal ini disebabkan karena masuknya produk subtitusi impor yang terbuat dari plastik dengan harga yang lebih rendah.Keadaan demikian berbeda dengan CV.Dandycraft yang mengalami pertumbuhan hasil penjualan sebesar $3 \%$ hal ini terlihat dari adanya peningkatan volume penjualan walaupun masuknya produk subtitusi impor yang terbuat dari plastik dengan harga yang lebih rendah. 


\section{Bagaimana Hasil Analisis Rasio Rentabilitas terhadap Hasil Penjualan} Kerajinan Tangan di Kecamatan Rajapolah Kabupaten Tasikmalaya periode 2005-2014.

\begin{tabular}{|c|c|c|c|c|c|c|}
\hline Nama CV & Tahun & $\begin{array}{l}\text { Volume } \\
\text { Penjualan }\end{array}$ & Modal Usaha & HasilPenjualan & Laba & $\begin{array}{c}\text { Renta } \\
\text { bilitasEkonomi }\end{array}$ \\
\hline \multirow{5}{*}{$\begin{array}{l}\text { CV. Jamal } \\
\text { Handycraft }\end{array}$} & 2010 & 28.300 & 509.400 .000 & 650.900 .000 & 141.500 .000 & $27,77 \%$ \\
\hline & 2011 & 31.100 & 715.300 .000 & 898.790 .000 & 183.490 .000 & $25,65 \%$ \\
\hline & 2012 & 32.900 & 888.300 .000 & 1.151 .500 .000 & 263.200 .000 & $29,63 \%$ \\
\hline & 2013 & 41.200 & 1.194 .800 .000 & 1.442 .000 .000 & 247.200 .000 & $20,69 \%$ \\
\hline & 2014 & 43.650 & 1.353 .150 .000 & 1.680 .525 .000 & 327.375 .000 & $24,19 \%$ \\
\hline \multirow{5}{*}{$\begin{array}{l}\text { CV Dandy } \\
\text { Handycrat }\end{array}$} & 2010 & 40.200 & 683.400 .000 & 864.300 .000 & 180.900 .000 & $26,47 \%$ \\
\hline & 2011 & 51.200 & 1.126 .400 .000 & 1.382 .400 .000 & 256.000 .000 & $22,72 \%$ \\
\hline & 2012 & 53.500 & 1.337 .500 .000 & 1.712 .000 .000 & 374.500 .000 & $28 \%$ \\
\hline & 2013 & 65.200 & 1.825 .600 .000 & 2.119 .000 .000 & 293.400 .000 & $16,1 \%$ \\
\hline & 2014 & 75.650 & 2.231 .675 .000 & 2.723 .400 .000 & 491.725 .000 & $22 \%$ \\
\hline \multirow{6}{*}{$\begin{array}{c}\text { Nucrea } \\
\text { Handycraft }\end{array}$} & 2010 & 29.000 & 552.000 .000 & 652.500 .000 & 100.500 .000 & $18,21 \%$ \\
\hline & 2011 & 33.200 & 763.600 .000 & 929.600 .000 & 166.000 .000 & $21,74 \%$ \\
\hline & 2012 & 35.500 & 923.000 .000 & 1.207 .000 .000 & 284.000 .000 & $30,76 \%$ \\
\hline & 2013 & 42.200 & 1.202 .700 .000 & 1.455 .900 .000 & 253.200 .000 & $21,1 \%$ \\
\hline & 2014 & 43.650 & 1.309 .500 .000 & 1.615 .000 .000 & 305.500 .000 & $23,33 \%$ \\
\hline & & 646.350 & 16.616 .325 .000 & 20.484 .815 .000 & 3.868 .490 .000 & $23,28 \%$ \\
\hline
\end{tabular}

Sumber: dan (Data Primer).

BahwaBerdasarkanTabel di atas terlihat adanya peningkatan laba walaupun nilainya fluktuatif selisih untuk setiap tahunnya yang terjadi di beberapa CV yang ada di KecamatanRajapolahKabupatenTasikmalaya. PertumbuhanHasilpenjualan yang terjadi di beberapa CV di kecamatanRaja polah Kabupaten Tasikmalaya menunjukan angka fluktuatif untuk setiap tahunnya walaupun hasil penjualan mengalami peningkatan hal ini disebabkan karena peningkatannya tidak begitu signifikan, keadaan demikian dipengaruhi oleh 
naiknya harga secara mayoritas untuk setiapTahunnya yang disebabkan naiknya bahan baku.

Berdasarkan hasil analisis Rasio Rentabilitas Ekonomi terhadap perbandingan antara Laba dengan Modal usaha pada industry kerajinan Tangan di kecamatan Rajapolah Kabupaten Tasikmalaya sebagai berikut :

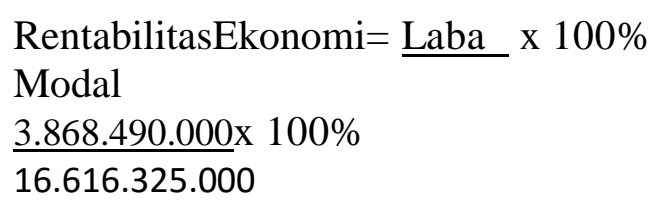

Bahwa berdasarkan kriteria dari Permen No. 14/Per/M.KUKM/XII/2009terhadap hasil perhitungan Rasio Rentabilitas Ekonomi yang menunjukan angka $23,28 \%$ hal ini menunjukan nilai $\geq 5$ dengan nilai 100 sehingga memperoleh nilai Sangat Baik artinya secara keseluruhan Industri kerajinan Tangan di KabupatenTasikmalaya dengan mengambil sampel di kecamatan raja polah telah menunjukan pertumbuhan yang Sangat Baik untuk dikembangkan menjadi salah satu potensi usaha dalam menopang perekonomian khususnya di KabupatenTasikmalaya.

\section{Kesimpulan}

Berdasarkan hasil penelitian pada industry KerajinanTangan di Kecamatan Rajapolah Kabupaten Tasikmalaya, penulis dapat mengambil kesimpulan sebagai berikut:

1. Bahwa Hasil penjualan industry Kerajinan Tangan di Kabupaten Tasikmalaya khususnya di Kecamatan Rajapolah telah mengalami peningkatan walaupun pertumbuhannya menunjukan angka fluktuatif naik turun hal ini disebabkan oleh beberapa factor yang mempengaruhinya yaitu terjadinya penetapan harga berdasarkan insting saja, terjadinya kenaikan bahan baku dan masuknya produk subtitusi impor yang terbuat dari plastik dengan harga yang lebih rendah. 
2. Bahwa Berdasarkan Tabel di atas terlihat adanya peningkatan laba walaupun nilainya fluktuatif antara selisih untuk setiap tahunnya yang terjadi di beberapa CV yang ada di Kecamatan Rajapolah Kabupaten Tasikmalaya. Berdasarkan hasil analisis Rasio Rentabilitas Ekonomi terhadap perbandingan antara Laba dengan Modal Usaha yang terjadi pada industry kerajinan Tangan di kecamatan Rajapolah Kabupaten Tasikmalaya diperoleh angka sebesar $23,28 \%$ hal ini menunjukan nilai $\geq 5$ dengan nilai 100 sehingga memperoleh nilai Sangat Baik artinya secara keseluruhan Industri kerajinan Tangan di Kabupaten Tasikmalaya dengan mengambil sampel di kecamatan Rajapolah telah menunjukan pertumbuhan yang Sangat Baik untuk dikembangkan menjadi salah satu potensi usaha dalam menopang perekonomian khususnya di Kabupaten Tasikmalaya.

\section{Saran}

Setelah penulis melakukan penelitian pada industry KerajinanTangan di Kecamatan Rajapolah Kabupaten Tasikmalaya, penulis dalamhalinimemberikan saran, diharapkan bermanfaat khususnya bagi industry kerajinanTangan yang ada di KabupatenTasikmalaya dalam mengembangkanusahanya, antara lain :

1. Strategi penetapan harga jual pada industry Kerajinan tangan di kecamatan Rajapolah Kabupaten Tasikmalaya disarankan tidak hanya menggunakaninsting saja,karena metode ini memiliki tingkat kekuatan prediksi sangat rendah, dimana pertimbangan penetapan harga hanya mengandalkan kecakapan dari pemilik perusahaan saja, tetapi perusahaan harus mengadakan analisis situasi persaingan terlebih dahulu, sehingga mempunyai tingkat prediksi yang lebih baik.

2. BahwaPerusahaan perlu menjaga stabilitas pertumbuhan hasilpenjualan, perusahaan disarankan untuk menetapkan strategi penetapan harga berdasarkan harga pesaing (competitive pricing) dengan mempertimbangkan faktor-faktor yang mempengaruhi strategi penetapan harga jual, sehingga diharapkan mampu menjaga stabilitas volume penjualan 
3. Perlunya peningkatan inovasi dan kreatifitas terhadap produk yang dihasilkan sehingga kualitas produk yang ditawarkan memiliki keunikan yang mendorong jumlah permintaan yang banyak.

4. Perlunya peningkatan perluasan pemasaran yang lebih luas dengan konsep manajemen yang baik.

5.

\section{DaftarPustaka}

Almilia, Spica, Luciana dan Kristijadi, Emanuela. 2012. Analisis Rasio Keuangan untuk Memprediksi Kondisi Financial Distress Perusahaan Manufaktur yang Terdaftar di Bursa Efek Jakarta. Jurnal Akuntansi dan Auditing Indonesia (JAAI), Vol 7, no 2, Desember 2003.

Arikunto, Suharsimi. 2010. Prosedur Penelitian. Jakarta: Rineka Cipta.

Asisi, Fransiskus. 2013. Landasan Teori Tingkat Pertumbuhan. http://asisiverry.blogspot.com (Di unduh pada 27 Maret 2015)

Riyanto, Bambang. 2013. Dasar-Dasar Pembelanjaan Perusahaan. Yogyakarta: BPFE.

Daniel, Moehar. 2003. Metode Penelitian Sosial Ekonomi. Jakarta: Bumi Aksara.

Herucahyono, Nugroho. 2013. 5 Strategi Terbaik Menetapkan Harga Jual Produk. https://blog.bukalapak.com (Diunduh pada 22 Mei 2015)

Ikatan Akuntansi Indonesia (IAI) .2004. Standar Akuntansi Keuangan. Jakarta: Salemba Empat.

Kasmir. 2008. Analisis Laporan Keuangan. Jakarta: Rajawali Pers.

Munawir. 2001. Analisis Laporan Keuangan. Yogyakarta: Liberti.

Sugiyono. 2009. Metode Penelitian Kuantitatif, Kualitatif da R\&D. Bandung: CV Alfabeta.

Sunyoto, Danang. 2014. Dasar-Dasar Manajemen Pemasaran. Jakarta: PT. Buku Seru.

Surakhmad, Winarto. 1989. Pengantar Penelitian Ilmiah Dasar, Metode dan Teknik. Bandung : Tarsito 
Widowati, Muderetno. 2010. Pengaruh Harga, Promosi Dan Merek Terhadap Penjualan. STIE Pelita Nusantara Semarang. Edisi September 2010, no 1, vol. 5, hal $55-69$. 